\title{
THE PUBLIC-PRIVATE MIX IN THE MODERN HEALTH CARE SYSTEM - CONCEPTS, ISSUES, AND POLICY OPTIONS REVISITED
}

\author{
Dov Chernichovsky \\ Working Paper 7881 \\ http://www.nber.org/papers/w7881
NATIONAL BUREAU OF ECONOMIC RESEARCH 1050 Massachusetts Avenue Cambridge, MA 02138
September 2000

The views expressed herein are those of the author and not necessarily those of the National Bureau of Economic Research.

(C) 2000 by Dov Chernichovsky. All rights reserved. Short sections of text, not to exceed two paragraphs, may be quoted without explicit permission provided that full credit, including (C) notice, is given to the source. 
The Public-Private Mix in the Modern Health Care System -

Concepts, Issues, and Policy Options Revisited

Dov Chernichovsky

NBER Working Paper No. 7881

September 2000

\begin{abstract}
Private financing of care can make universal entitlement to care more "comprehensive" and "complete". The possible combination -- at the point of service provision -- of privately acquired entitlement with the public entitlement, can impinge, however, upon the goals (e.g. improved health, equity, cost containment, care production efficiency, and client satisfaction from service) of the publicly supported health system. The potential to achieve these goals is at greatest risk in the "combined system" (e.g., Australia) where, contrary to the "segregated system" (e.g., Canada), the same providers are sanctioned to provide medical care under both private and public contracts. A combined system may be inevitable, however, for both economic and political reasons, especially where medical resources are relatively scarce. In this case, the Emerging Paradigm in health systems can offer the best possible solution to the public-private mix issue. In this paradigm, budget-holding institutions, intermediaries between financing entities and providers, organize and manage the consumption of care (OMCC) under public entitlement. The OMCC institutions can offer private insurance, to supplement to the 'public insurance', but supervise separate groups of providers, those working under public contracts and those working under private.
\end{abstract}

Dov Chernichovsky

Department of Health Policy and Management

Faculty of Health Sciences

Ben Gurion University of the Negev

Beer-Sheva. Israel

and NBER

Tel: $\quad 972(0) 76477421$

Fax: $\quad 972$ (0) 76477634

Email: dov@bgumail.bgu.ac.il 


\section{Introduction}

Modern health systems such as those in the Organization for Economic Cooperation and Development (OECD) member states, with the notable exception of the USA, are designed to ensure that their citizens are universally entitled to a publicly supported package of medical care. This package is delivered through a health care system ideally characterized by economic and organizational features that promote social equity; prevent unchecked expansion of national health expenditures that can adversely affect the economy; improve care production efficiency; and enhance client satisfaction with care and service (Chernichovsky 1995a).

The integration of privately acquired entitlement with the publicly supported entitlement can seriously impinge upon the character of the publicly supported system; it can defy its very raison d'etre, which is to promote these goals while correcting the market failure associated with private financing of medical care (Arrow 1963). Indeed, the public-private financing mix in the health care system is probably one of the most confusing, hotly debated, and challenging issues in the modern system. It is essential therefore to examine how to integrate private funding, particularly privately financed 'co-payment', 'extra billing' and 'supplementary insurance', into the publicly supported system. Such an examination should be objectively focused and as free as possible of the ideological baggage that frequently intrudes into discussions of the public-private mix in the health care system.

This paper constitutes an attempt to make such an examination. It provides a policy framework for the public-private mix, definitions of pertinent concepts, a review of the issues, and an outline of the policy options, including those involving the emerging paradigm in health systems. 


\section{A Policy Framework for Public Entitlement}

Public entitlement to care has three dimensions: 'universality' 'comprehensiveness', and 'completeness'. The first refers to the proportion of the population that benefits from public entitlement. The second, to types or categories of care (e.g., dental, longterm care, etc.) included in the public benefits package. The third dimension concerns the completeness of care within categories. While the first dimension is easily identifiable and measurable, the other two are not, and may be at times hard to separate. This follows because the conceptualization of medicine as a unique field of endeavor is swiftly changing, and the change involves complex technological and social factors. ${ }^{2}$ Consequently, the issues of what should be included in medicine, both as 'category' (e.g., treatment of addictions) and as treatment within a category (e.g., use of a particular drug), is rather intricate. Yet, it is by-and-large possible to separate treatments by this typology.

Suppose that we order public entitlement or benefits along those three dimensions from most to the least cost effective, and the axes in Figure 1 represent the percentage of coverage along each dimension. The curved plane $\mathrm{H}$ is an iso-health plane, indicating the combination of public entitlement, involving the three dimensions, that yield a particular level of health, $\mathrm{H}_{0}$ in this case, in the population. ${ }^{3}$ That is, movement along this plane indicates tradeoffs along any dimension that is required to maintain a particular level of health, measured, say, in Disability Adjusted Life Years

\footnotetext{
${ }^{1}$ For the generality of discussion and to deal with 'co-payment' that is discussed in the next section, I consider the possibility that the service is not necessarily entirely free under public entitlement.

2 For related discussions, see Antonovsky (1987), Williams and Calnan (1996), and Schneider et al. (1992).

${ }^{3}$ When all dimensions reach $100 \%$, the planes converge into a theoretical point (the upper most corner of the 'box' spaced by the three dimensions). To be meaningful, the space has a minmum level of universality, $\mathrm{U}_{\min }$, and when fully universal has minmum levels of comprehensivenes and completeness denoted by the the rim of the plane $\mathrm{H}$.
} 
Saved (DALYS). Higher planes (not shown) indicate higher levels of health associated with them.

The flat plane $\mathrm{B}$ indicates the various combinations a given public budget $\mathrm{B}_{0}$ can be spent on the different dimensions of entitlement. For any given Budget $\mathrm{B}\left(\mathrm{B}_{0}\right.$ in our case) and iso-health possibilities ( $\mathrm{H}_{0}$ in our case), optimal entitlement would be at the point $\mathrm{O}_{0}$. Any deviation from this point means that to attain health level $\mathrm{H}_{0}$, a higher budget is required.

Figure 1: The Domain of Public Entitlement and its Efficient Allocation

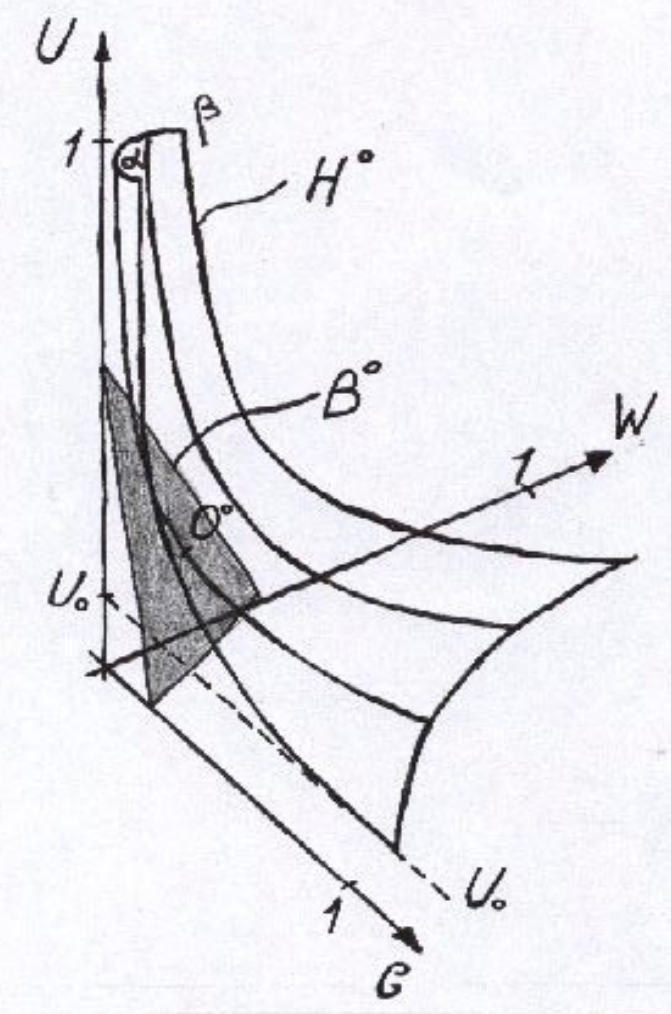

This presentation suggests, thus far, that in a world with limited resources there is a tradeoff between universality, comprehensiveness, and completeness of care. Although the rhetoric in publicly supported systems leans toward the 'solidarity 
principle' whereby everybody gets what he needs, reality is consistent with the 'fairness principle' whereby if a treatment cannot be extended to all, it is denied altogether to the entire population. That is, while universal entitlement, which is the rule, strives to be 'comprehensive' and 'complete', this is impossible. ${ }^{4}$ Moreover, universal entitlement does not necessarily yield an optimal level of health, especially at low resource levels.

The discussion that follows considers situations where public entitlement is 'fully' universal $(\mathrm{U}=100 \%)$, the common case among developed nations. The public-private mix entails using private funds, say by an individual representative of the population, to move along the directions indicated by the arrows $\mathrm{A}, \mathrm{B}$ or combination thereof (Figure 2). Movement along A indicates private funding on medical categories and services within categories that do not change levels of health, $\mathrm{h}_{\mathrm{o}}$, beyond those attained through public entitlement. Movement along B indicates private spending that can increase the health status. That is, the first might be considered wasteful, while the second not.

Figure 2: Potential for Privately Financed Care Under Universal Entitlement

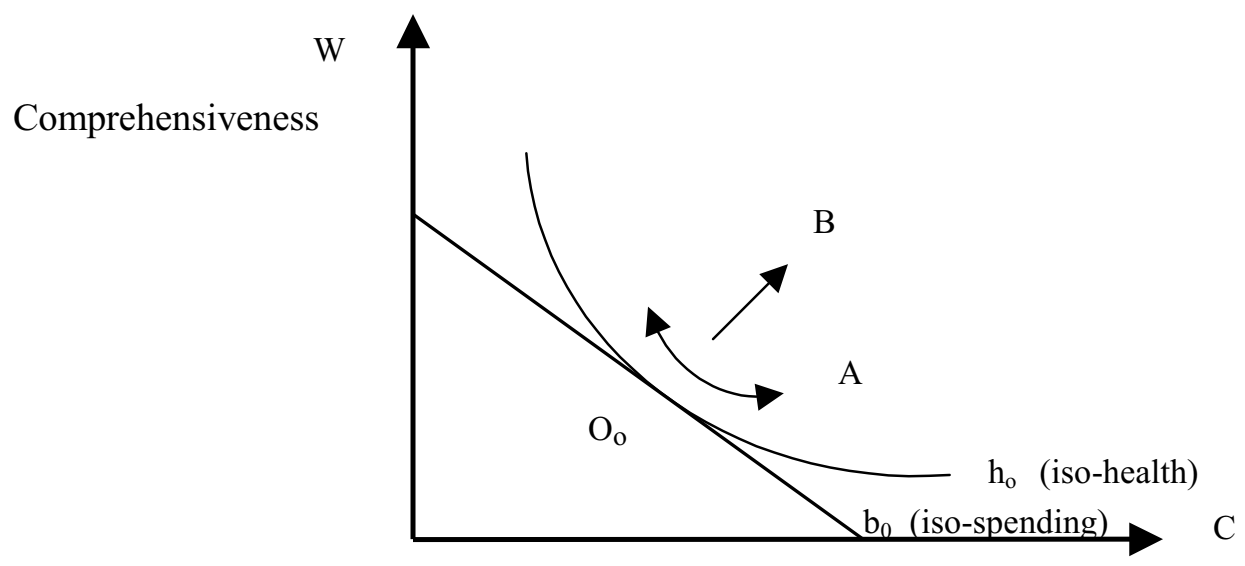

Completeness

4 Both 'need' and 'comprehensiveness' are hard to delineate and compare, however, partly because they concern perception and expectation as well medical technology and approach. 
A prudent public policy calls for inclusion in public entitlement care that maximizes the health status of the population and other potential health system goals or benefits (e.g., equity) per extra dollar of public spending. Namely, if universal entitlement is mandated, public entitlement should yield the situation indicated by $\mathrm{O}_{\mathrm{o}}$ (Figure 2). Otherwise, the representative, fully informed, and rational consumer, would try to use his private funds to correct for the inefficiency in public entitlement, by moving toward points like $\mathrm{O}_{\mathrm{o}}$.

Three basic parameters affect the relevant policy outcome. The first is the demand elasticity of the option confor inclusion, with an additional budget. This parameter determines the change in the quantity demanded or in the medical care utilization response following a new public subsidy or drop in price of service that follows public entitlement. As such, this parameter determines the effect of a public subsidy (public entitlement) on (a) access to care, horizontal equity, and (b) the income distribution, vertical equity. ${ }^{5}$ Excluding from public entitlement a service with low demand elasticity would, relatively speaking, affect little the use of the service (access) but would cut heavily into the household's income. The converse holds for a service with high demand elasticity.

The second parameter is the health production elasticity of medical care. This parameter concerns the efficacy of the service or the potential gain in health status due to the demand or utilization response. The higher this elasticity, the higher the health benefits from improved use of or access to service. The demand and production elasticities combined determine the cost - effectiveness or efficiency of particular 
public benefits. ${ }^{6}$ The more health gain per dollar spent, the more efficient is the policy. The third parameter is the supply elasticity of the medical service under consideration. This parameter determines the potential increase in quantity demanded, given the extra budget to expand public entitlement. ${ }^{7}$ The higher this elasticity, the higher the possibility to expand the quantity demanded of a given service with a given budget. Under generalized demand and health production elasticities, and given supply conditions, the likely policy outcomes are summarized in Table 1.

Table 1: Efficiency and Vertical Equity Gains of Public Entitlement (Price Subsidy) by General Levels of Demand and Health Production Elasticities

\begin{tabular}{||c|c|c||}
\hline \multirow{2}{*}{ Production } & \multicolumn{2}{|c||}{ Demand Elasticity } \\
\cline { 2 - 3 } Low & Low & High \\
\hline \multirow{2}{*}{ High } & Efficiency - low & Efficiency - intermediate \\
& Vertical Equity - high & Vertical Equity - low \\
& Efficiency - intermediate & Efficiency - high \\
& Vertical Equity - high & Vertical Equity - low \\
\hline
\end{tabular}

The 'intermediate' efficiency outcomes follow either a high demand response combined with a low 'health production' effect or vice versa. In this generalized world, there is a likely tradeoff between (vertical) equity -- the income distribution effect of any policy -- and its efficiency. This follows because the efficiency aspect is a function of the demand response combined with the health production response,

\footnotetext{
${ }^{6}$ Suppose that medical services (M) are inputs along with a vector of other inputs (X) in a health production function, $\mathrm{H}=\mathrm{h}(\mathrm{M}, \mathrm{X})$ where $\mathrm{H}$ is measured by some common outcome measure (e.g., Disability Adjusted Years of Life Saved - DALYS). If $M$ is a function of its price (P) and a vector of other factors including income and prices of other products $(\mathrm{Y})$, then $\mathrm{M}=\mathrm{m}(\mathrm{P}, \mathrm{Y})$. Hence, $\mathrm{H}=\mathrm{h}[\mathrm{m}$ $(P, Y), X]$, and $(d H / d P)=(\delta h / \delta m) d m / d p$. In elasticity terms: $E_{H P}=E_{H M} E_{M P}$, where $E_{I J}$ is the elasticity of I with respect to $\mathrm{J}$.

7 See Appendix.
} 
while the vertical equity aspect is a function only of the demand response. Therefore, as policy guidance in general, the following principles hold:

- For given supply conditions, the higher the demand elasticity, the lower the public outlays for any given increase in the quantity of service demanded or use of service.

- For given demand conditions, the lower the supply elasticity, the higher the publicly based outlays needed for a given increase in quantity demanded following public entitlement.

That is, from the health status perspective, the supply and the health production elasticities being equal, a prudent policy should seek to include, in public entitlement, the options that have high demand elasticity. Those are usually associated with larger populations.

However, there may be a fallacy in this conclusion. In a fully rational world with full information and certainty, consumer demand for medical care follows the demand for health (Grossman 1972). That is, a priori, the more efficacious or utilitarian care is, the lower its demand elasticity or the higher the client's willingness to pay for any amount of care. Hence, in an ideal world, relatively high demand elasticity should be associated with low production elasticity and vice versa. In this world, a prudent policy should call therefore for the low demand elasticity options that reflect high health production elasticities, contrary to the earlier conclusion. However, the world is imperfect due to consumer ignorance and providers ability to affect demand. These can call for movements of type A in Figure 2. Demand may therefore be relatively inelastic for non-efficacious care.

The discussion thus far underscores the information challenges for policymaking - - knowledge of pertinent elasticities - - and the potential tradeoffs facing policy 
makers. It also has two major implications for public policy. These are in many ways the raison d'etre for public intervention in the health system. First, government should leave to private financing the less efficient or less cost-beneficial options. This rule serves both efficiency and cost containment objectives. These options may indeed have negative vertical equity or income distribution implications, but these can be handled by other policies, outside the realm of the health system, such as by general taxation.

Second, and in close association with the previous argument, the government should educate the public about medical processes and health outcomes. By educating clients and modifying their demand according to the effectiveness of treatments, the government could increase demand elasticity for relatively ineffective treatments. The government would thereby not only avoid unnecessary transfers of incomes from clients to providers, but would also improve vertical equity in conjunction with its policy. Moreover, informed consumers can help implement an efficient policy by having their demand elasticities better synchronized with the efficacy of care.

\section{Copayment}

Copayment $(\mathrm{CO})$ is the most common form of private finance that can be integrated into public entitlement. CO serves either of two objectives, or the two combined (a) to offset, at least in the short term, 'unnecessary demand', and (b) to raise funds for the public system. The two often become confused, however, partly because even when $\mathrm{CO}$ is initially conceived and implemented as a means for achieving the first objective, it eventually becomes an indispensable source of income for the public system, thus serving the second objective. The problem is that the two objectives call for entirely different approaches to CO. Consequently, clarity about 
the real or dominant objective is necessary for a prudent policy because $\mathrm{CO}$ affects the ultimate goals of the health system.

Two parameters are pertinent: the demand elasticity for care, and the level of copayment that is insurable. If the main objective of $\mathrm{CO}$ is to reduce demand, the government should opt to impose a $\mathrm{CO}$ on a service / product with a relatively high demand elasticity. It should also forbid insurance of the copayment, or, at best, permit a small portion of the copayment to be insured. Private insurance, like 'public insurance', usually effectively reduces the price of service at the point of service and raises the quantity demanded and the amount of (private) spending. In this case, an appropriate policy, which maximizes the reduction in demand, has relatively little fund-raising potential. Moreover, it may harm access to care or horizontal equity, and as suggested in the previous section, if this care is relatively efficacious, it may also harm the health status of the population.

If, however, the purpose of $\mathrm{CO}$ were to interfere as little as possible with demand for care, but to maximize the fund-raising potential of the $\mathrm{CO}$, the government should impose the $\mathrm{CO}$ on a service/product of low demand elasticity and sanction insurance of the CO. Thereby, the $\mathrm{CO}$ adversely affects vertical equity, but minimizes the potential adverse effect of its policy on horizontal (access) equity and on health. The insurance option can make the added funding more equitable.

\section{Basic Concepts and Patterns of Public-Private Mix}

For the purposes of structure as well as to avoid common confusion, the ensuing discussion of our topic requires definitions of basic concepts, and characterization of the nature of the market or institutional arrangements for private finance in conjunction with public finance of care. As for services and financing options, the following are defined: 
- $\quad$ Public Finance Principles (PFP) - Finance of medical services derived from income-based or risk-based mandatory contributions. Such contributions need not necessarily all be channeled through the government's budget (Chernichovsky, 1995a, 1997).

- $\quad$ Public Benefits Package or Basic Package (BP) - Medical services every citizen is entitled to receive that are financed according to public finance principles.

- $\quad$ Public Contract (PC) - A contract for the medical services comprising the BP that are paid for or funded by funds raised through PFP, irrespective of ownership of the provider facility and the civil service status of the provider. ${ }^{8}$

- Excluded Medical Services (EMS) - 'Recognized' medical services that are not included in the BP.

- Amenities (AM) - Goods and services of a 'non-medical' nature that can be purchased in conjunction with medical care.

- Quality Public Benefits or Basic Package (QBP) - Actual or presumed quality adjusted BP.

- $\quad$ Private Public Benefits Package (PBP) - Services (of a given quality) included within the basic benefits package, but purchased with private funding under a private contract. $^{9}$

\footnotetext{
${ }^{8}$ Indeed, in the majority of OECD countries, services are under public contracts, with suppliers and contractors who are not 'public' in the sense of being owned by the government. They are either forprofit or not-for-profit organizations working under a public contract, as defined here. This definition is broader than that used originally by Hurst (1991).

${ }^{9}$ QBP and PBP might be used interchangeably, because a PBP is invariably purchased to obtain a real or perceived QBP, often to obtain the same service, but, say, more quickly.
} 
- Ancillary Services (AS) - Services of any type (AM, EMS, QBP) not included in the BP and purchased under a private contract, as opposed to acquisition through a public one.

- $\quad$ Supplementary Package (SP) - Ancillary services supplied by contractors/providers operating under a public contract.

- $\quad$ Extra Billing (EB) -Payment for SP under private contract.

- $\quad$ Private Insurance (PI) - Privately funded insurance fully or partly covering the cost of ancillary services.

The scope for the SP involving EB, and potentially PI, is illustrated in Figure 3, showing all the possible combinations that can comprise the SP.

Figure 3: Possible combinations of ancillary services (AS) and the potential for private finance

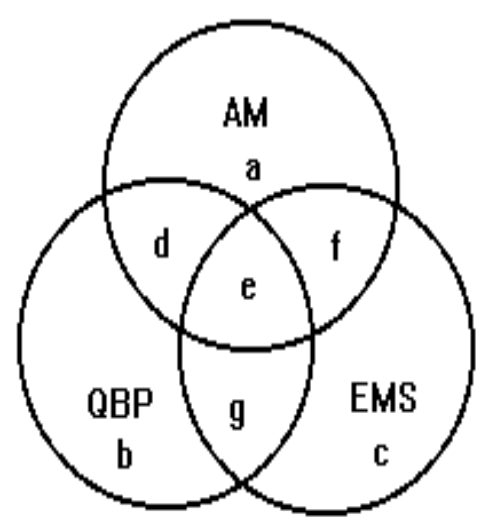

The three possible markets or institutional arrangements or public-private mix situations are illustrated in Table 2. In the purely private subsystem, providers who are not permitted to have public contracts supply any AS of any possible combination (Figure 3). That is, a SP is prohibited. This might be the case, at the extreme, even if the provider institution is not privately owned, as can be found now in former Eastern 
Block nations (box 1, Table 2). In the purely public subsystem, the BP is provided by suppliers, of any type of ownership, who have only public contracts (box 3). ${ }^{10}$ These two subsystems can coexist in the same segregated health system. In this system, privately owned provider institutions must choose the type of contract under which they will operate. ${ }^{11}$ In the combined health system, service providers, irrespective of the type of ownership, are sanctioned to supply services within the framework of either private (privately funded) or public (publicly funded) contracts (boxes 2). That is, in this case providers are allowed to provide a SP. ${ }^{12}$

Table 2: Possible Funding and Service Provision Options

\begin{tabular}{|l|c|c|}
\hline $\begin{array}{l}\text { SOURCE } \\
\text { OF } \\
\text { FUNDING }\end{array}$ & $\begin{array}{c}\text { Private (including private } \\
\text { insurance) }\end{array}$ & $\begin{array}{c}\text { Public (including mandatory } \\
\text { contributions not channeled } \\
\text { through the state) }\end{array}$ \\
PROVIDER & & \\
\hline Private & & (2) Combined system \\
\hline Public & (1) Purely private subsystem & (3) Purely public subsystem \\
& (2) Combined system & \\
\hline
\end{tabular}

A fully segregated system, applicable to all the options for private finance, is almost non-existent. The key issues are authorization of the combined system, and if sanctioned, its exact nature. These issues, which affect providers' incentives and

10 This particular consideration does not apply to medical goods and services which are parts of the BP but which are subject to a copayment.

11 Inclusion of insurers and organizations that organize and manage care in this scheme follows further in the discussion.

${ }^{12}$ It is noteworthy that while paying privately for service is a client's prerogative, he can rarely choose not to contribute to the public system because he pays/insures for services privately. Excluding Germany, which allows the top income decile to 'opt out' of mandatory insurance schemes, no modern 
opportunities to enhance providers' interests, need to be assessed vis-à-vis their potential influence on the health system's goals.

\section{The BP and the Underlying Incentive System}

So far, the discussion has assumed a well-defined BP, understood by patients and providers. However, the attempt to define a medical BP is likened to chasing after rainbows. Even about existing technology, a concurrence of opinion can be rare among physicians, especially when one considers the problem of dealing with constantly changing technology. This state of affairs intensifies the problem -- which underlies public involvement in the health system-- of information asymmetry between patients and providers.

Consequently, the use of the term supplementary package to the $\mathrm{BP}$ might be misleading at the outset. It implies that a well-defined package of benefits, understood by patients or even the state, does in fact exist, part of which is publicly funded, and the remainder, whatever its nature, is to be privately funded. However, no such package can be definitively set, and there is no limit, in terms of services and payment, to the 'supplemental' elements, to make service either more 'comprehensive' or more 'complete'.

Economic theory predicts what appears to be borne out by reality, as suggested further in the discussion, that the combined system, as defined above, allows:

1. Exploitation of the status and condition of the patient in order to justify privately paid services, especially, as is most likely the case, when the socioeconomic circumstances of the patient are known to the service provider.

2. Utilization of publicly supported infrastructure and resources for encouraging the demand for privately paid services. 
The first follows the natural and justifiable interests of service providers in augmenting their income and obtaining other utilitarian benefits (e.g., seeing interesting cases, doing research). The ensuing 'exploitation' is a consequence of an ill-informed consumer, especially one who might be 'of interest' to the provider, that is, one who has the financial means to pay for service (either directly or indirectly, through private insurance). This interest is implemented primarily through referrals from a public to a private practice of the same provider, either on the premises where he operates under the 'public contract' or on other premises. ${ }^{13}$ Alternatively, there can be collusion between providers operating under different contracts, whereby providers working under public contracts refer patients, for a 'commission', to providers working under private contracts.

The second tendency listed above, which usually follows from the first, is related to the service provider's incentive to promote his private practice through the publicly-funded subsystem by using, when possible (usually when facilities are budgeted), the infrastructure of this subsystem for private practice. In this way, by saving on inputs in the private practice, the service provider lowers the cost of the services to himself. He can pass on part of this saving to the client. In addition, for the more expensive treatments, an extension of the private practice, the patient can always be referred back to the publicly supported system. Consequently, when compared to the situation where the client needs to pay privately for the full service, including the elements provided through public finance, he benefits from lower costs that enhance his demand for private service. Although practically illegal, it is common in Israel, for example, for practitioners under public contacts to refer patients

13 This is considered as the exercise of discretionary and discriminatory monopoly powers by the provider vis-a-vis his patients. 
treated under such contracts to the practitioner's private practice. However, for expensive procedures, the patient is referred back to the publicly supported system. The specific incentives of providers depend on the ways providers working under public contracts are compensated. The incentives to exploit the client may be highest where providers are reimbursed through prospective mechanisms i.e., wages, capitation, or DRGs, and least when reimbursed through retrospective mechanisms i.e., fee for service (Chernichovsky 1997).

It is clear that the combined system provides the best opportunities to exploit the ignorant patient and the public infrastructure. Within this system, the risk of exploitation and its potential impact on the system's objectives depend on the nature of services that are subject to extra billing and private insurance.

\section{Public-Private Mix and Health System Objectives}

About amenities (AM) which constitute part of AS or SP, the differences of opinion surrounding their status are essentially ideological. Ignoring the ideological element, it is possible to adopt the position that amenities, these patently non-medical goods and services, could be included in a supplementary package (by-and-large provided in hospitals) without adversely affecting any objectives of the health system. This position is based on the assumption that patients (or their family members) who are willing and able to pay are fully capable of judging the need for those items or services that lack any apparent medical significance. Even in this case, the issue arises whether the medical staff would discriminate, if only for purely psychological reasons, in favor of those predisposed to allow themselves extra 'comforts'.

Consequently, including amenities in the SP that are largely not subject to insurance is not particularly problematic, provided that they do not include goods and services that: (a) might have medical implications for the purchasers and their fellow patients, 
and (b) could be subsidized by public funds. That is, we might consider provision of a BP plus privately financed AM as still part of a purely public subsystem, as this free choice does not infringe on any systemic objective. Or, it is the least damaging to those objectives.

As for the options for AS that are non-amenities, that is, excluded medical services (EMS) and a quality basic package (QBP), it is useful to group them into two categories. The first category includes EMS that are complementary (EMSc) to services included in the BP, plus EMS that are neutral (EMSn) vis-à-vis the BP. ${ }^{14}$ The second category includes substitute EMS (EMSs) for those in the basic package, and services considered as Quality Basic Package (QBP). These concepts relate to the comprehensiveness and completeness aspects of entitlement discussed earlier. EMSc concerns the completeness of entitlement, while EMSn the comprehensiveness.

EMSc - that is, drugs prescribed while a person is being treated under a public contract, but that need to be purchased privately -- can include any service that is an extension of public entitlement. In this case, the patient needs to obtain privately an element of diagnosis or treatment that has been initiated under public entitlement. When EMS are 'neutral' vis-à-vis BP services -(e.g., dental or long term care not included under public entitlement) the EMS and the BP are considered functionally unrelated. $^{15}$

EMSc and EMSn do not represent mutually exclusive options; publicly funded health systems act on both EMSc and EMSn concurrently operating on the different

\footnotetext{
14 The reader should avoid potential confusion between copayment and payment for EMSc. Copayment is a compulsory payment, part of the cost for a service included in public entitlement. EMSc is part of a service that is not included under public entitlement. Confusion may arise, especially when the EMSc are subsidized nonetheless.

15 It is often complicated to separate medical situations, e.g. dental problems from other internal problems.
} 
dimensions of public entitlement as suggested earlier. EMSc limits the completeness of public entitlement, while EMSn limits the comprehensiveness of care under public entitlement. At the margin, it is not clear a priori which of the two, EMSc (completeness) or EMSn (comprehensiveness), should be included in public entitlement. Making a choice between the two options (as well as between any combination of them) needs to be based on cost-benefit considerations as discussed above.

This general principle notwithstanding, EMSc and EMSn represent distinct options in a world of limited resources in general and of public-based financing in particular, because of the a priori 'indivisible' nature of EMSn and the political economy of health systems. Inclusion of EMSc constitutes movement along intensive margins while inclusion of EMSn constitutes movement along extensive margins. And, as a result, some general policy risks can be outlined when one option is compared with the other. In the case of EMSc, for completion of treatment, the patient is prescribed a private contract. Consequently, his demand elasticity for this contract is low; the patient is practically compelled to buy the private service regardless of his income. This is the equivalent to a regressive tax, which adversely affects vertical equity. ${ }^{16}$ Moreover, as the patient's ability to pay becomes a factor in both providers' and patients' decisions, choice of treatment technology will be ultimately affected by this ability. At the extreme, even the publicly financed part of the services can become void when the patient cannot afford the privately financed part. These issues adversely affect equality in access to care, and vertical equity, and can be detrimental to the efficiency of standing public entitlement. In this case, if EMSc are part of the

\footnotetext{
16 Particular groups can always be exempted from the private contract.
} 
SP, the provider has the highest leverage on the patients, as is the case of extra billing for drugs in Japan, for example.

Indeed, concerning EMSc, in principle the basic approach in developed nations is that if particular medical services are cost-beneficial from a medical standpoint, then they should be part of the BP. ${ }^{17}$ This follows because of the lack of a correlation between the level of expenditures on medical care and the level of health found in the population (OECD 1990). This lack of correlation suggests that public entitlement may include services that are not cost beneficial, and that should be excluded from this entitlement; public entitlement and its organization and management should minimize unproductive health care spending. This can be achieved, as suggested above, by fully including the most cost-beneficial services in public entitlement (and by educating the public about the others). Functional disruption of treatment along public or private lines can adversely affect the efficiency of public entitlement.

EMSn may best represent the resources limitation problem, especially in systems with universal entitlement, given the challenges these services present. Financially, it is easier to add a service to a category included in public entitlement than to add an entire category of service. In general, for both EMSc and EMSn, the 'fairness' principle may rule; that is, what cannot be provided to all is provided to none. The principle is more easily applied to EMSn than to EMSc. Technological progress and political-economic concerns about adopting new technology reinforce the tendency to add to included services rather than adding a new category. Including only part of a particular EMSn in public entitlement because of budgetary limitations turns the excluded part of the said services into EMSc. This entails the risk just mentioned-voiding even the pertinent public entitlement, at least for those who cannot afford the

17 The reader is reminded that copayment issues are not part of this consideration. 
EMSc. In addition, once a service is included in public entitlement, it is politically hard to exclude it, even in view of the advent of more cost-beneficial, yet excluded services. Israel, for example, has almost no dental care under public entitlement, in spite of considerable evidence for its potential contribution to people's health (Chernichovsky and Horev 1999). At the same time, other probably less costbeneficial care is included under public entitlement. The historical exclusion of dental care is based on financial considerations. Today dental care cannot be 'traded' in the public package for less cost-effective and less equitable care already included in public entitlement. Almost by definition, an EMSn cannot constitute part of a SP, and therefore does provide an opportunity to take advantage of the patient.

The second set of EMS and QBP includes those that are substitutes (EMSs) for services included in the BP under public entitlement. Almost as a matter of definition, these include QBP -- services that are included in the BP, but are presumed to be superior to those in the BP and can be procured only under a private contract. A common case would be brand name drugs versus generic drugs. In this case, the two types of services, under public and private contracts, are considered medically indistinguishable. As suggested earlier, the government should include services on the basis of cost-benefit considerations, and educate the public about brand name products or services. $^{18}$

Matters become rather complicated when there is a practical and real dimension to

${ }^{18}$ It is possible to attribute to the state a Machiavellian approach, whereby the state implicitly fosters private demand for brand names, etc., to lower demand for, and public spending on, services under public entitlement. As the demand for brand names has a high-income elasticity, this is in fact a progressive tax-like approach to supporting the public system. While this might be considered a reasonable policy, it defies the equity and spending-control rationale for public intervention. This approach is particularly problematic in the case of services, contrary to goods (drugs) because the supply of manpower is less elastic or responsive to price changes than goods. Consequently, any promotion of private demand for service would contribute to inflation and under-the-table pay, thus denying altogether, services to those who do not pay. 
the EMSs cum QBP. Problems usually revolve around scheduling diagnosis and treatment, and choosing physicians. With regard to the first, there is a tendency to confuse two issues: first, the very existence of waiting lists and second, the 'means' by which they may be shortened. Economists tend to s'reasonable' waiting lists as a lesser evil. Such lists can indicate the absence of excess capacity in the health system, especially in view of providers' inclination in the publicly funded system to create waiting lists as a means to increase capacity under the public contract, as well as to promote private contracts to shorten the lists. This inclination contributes to the rise in health expenditure without necessarily raising the average level of health status in a population. It should be stressed that through appropriate incentives, it is possible to shorten waiting lists in this system without resorting to the QBP option as part of a SP.

The matter of choosing a physician involves the issues already raised above, that is granting private contracts to providers who have public contracts, as well as patients jumping the queue by choosing a particular physician.

Consequently, the relevant question in the context of EMSs and QBP concerns not the actual existence of a waiting list in a publicly funded system. Rather, the question is "Within a publicly funded system, should those 'thrown' to the end of the line or handed over to inexperienced physicians necessarily be those unable to pay for (or to insure themselves for) those privileges?"

Moreover, suppose most or the entire population was to insure for or was capable of buying these privileges? Would there be any gains? Clearly, both equity and cost containment objectives are undermined when providers who have public contracts offer EMSs or QBP. 


\section{A Tale of Two Nations}

Canada and Australia have health systems that are of particular importance for the purposes of this discussion. The two nations are similar to one another economically, culturally, politically, and administratively. These two federations maintain universal entitlement to a BP by means of taxation. ${ }^{19}$

Regarding ancillary services (AS) or a supplementary package (SP), the approaches implemented by Canada and Australia are almost polar opposites, to the extent such opposites can exist. In Canada, an almost complete separation between the public and private systems was instituted in 1986, primarily by means of legislation regarding the granting system operated by the federal government. This system practically prohibits community physicians who treat patients under public contracts from having private contracts or from receiving private compensation, either directly from the patient or indirectly from an insurer. The same applies to statefunded hospitals. Hence, the private system is separate from the public one; that is, Canada has situations (1) and (3) shown in Table 2, existing side by side; it has a segregated system.

In Australia, the 1984 National Health Insurance Law declared that the SP would essentially contain rather broadly defined ancillary services. The Australian system entitles the individual to pay providers for AS either directly or indirectly, even if the providers operate under the terms of a public contract. Within the framework of community medicine, the SP covers AS that are not included in the publicly funded entitlement, such as dentistry and pathology (laboratory exams) that is not prescribed by a recognized practitioner. In cases of hospitalization, the Australian SP covers private hospitalization. Broadly defined amenities are allowed in publicly funded or

\footnotetext{
19 To some extent, the European analogues to these two situations would be the British and French systems.
} 
'recognized' hospitals. ${ }^{20}$ An individual interested in private hospitalization is entirely free to purchase such services directly or through private insurance. He will not get any state reimbursement if the individual stays in a private hospital that is ineligible for government funding.

Private insurance, now $30 \%$ subsidized by the government, only covers up to the level (schedule) set by government: the individual cannot insure against payments beyond those levels. Hence, the Australian government oversees all service prices, and does not allow the use of insurance to cover 'unlimited costs'. By these means, while containing the level of health expenditure, the government also guards the citizen against possible exploitation by service providers.

Furthermore, private insurance companies in Australia are required to accept every potential subscriber at a uniform rate (the community rate) for each subscription plan. It is possible for insurers to charge different rates for the insurance packages or plans they offer. However, each individual subscriber within each package or plan is insured at a uniform insurance rate, independent of age, risk factors, or income. In this way, privately funded insurance in Australia helps maintain equity, compared with a regular private insurance scheme, and has a system, which is in many ways supplementary to state insurance.

In spite of the above, the following developments have been observed in Australia:

1. The relative share of private funding of 'public' hospital costs has been increasing over the years.

2. Public hospitals, whose income is derived from public sources, prefer to accept patients who either pay directly or who carry private (supplementary)

\footnotetext{
${ }^{20}$ It is important to emphasize, once more, in this case as well, that the majority of Australian hospitals that are recognized as public hospitals are not state-owned. In principle, the hospital owners have to decide on the market in which they operate.
} 
insurance, despite the fact that these patients generally do not receive any additional services (The Manchester UFS 1991, Waldby n.d.).

3. There has been an increase in those elements of community service (examinations, etc.) for which individuals are either entitled to pay or for which they are entitled to privately insure themselves (Deeble \& Lewis-Hughes, 1991).

Despite the above, there is no conclusive evidence to indicate that patients with supplementary insurance receive different or better service than those who receive such services within the public system, particularly in hospitals (The Manchester UFS 1991). In addition, high-income individuals tend to insure themselves privately. However, the elderly in every income group tend to do so at a time in their lives when their judgment concerning both their rights and the nature of supplementary insurance is dwindling, while their anxiety is increasing (Wilcox 1991).

It is noteworthy that when governments are faced with the Australian type 'combined' system, they resort to national overriding measures to preserve cost controls and equity. These measures may diminish the freedom of choice in general. Consider, for instance, the cases of Germany and France. Both countries offer a very liberal SP, including elements which are contained within public entitlement, covered by mandatory insurance. To counter the adverse consequences of the SP on national health expenditure, in both countries the state imposed system-wide restrictions, rather than restrictions on that part of the system that operates within the framework of public contracts. The most widely discussed current example of this is the maintenance of a rigid national prescription registry, which permits the registration, and the consequent prescription, of generic drugs only. Thus, in Germany and France, even those who wish to purchase certain drugs in the private market, outside the framework of the mandatory insurance system, may no longer be able to do so. This 
means that whatever goals the state cannot achieve by means of its selective control mechanisms within the 'public part' of the system, it achieves by means of blanket regulations imposed on the national system, private as well as public.

The problem presented by the Australian system and others alike emphasizes the reasons for adopting a Canadian solution practically imposing a segregated system. Indeed, the Canadian developments are particularly relevant in light of the Australian experience. Approximately 11 years after Canada adopted national health insurance, a special investigative commission was appointed to examine two issues. First, were the provinces transferring payments designated for federal health programs to other non-health-related programs? Second, what was the influence exerted on the rest of the system by the extra-billing? At the head of the commission was Mr. A. Hull, who had formerly served as chairman of the committee (1961-1964) which formulated the principles underlying Canada's national health insurance. This committee originally sanctioned the institution of a supplementary package. In other words, those who had initially authorized this provision then made the following recommendations: "If extra billing is permitted as a right practiced by physicians at their sole discretion, it will, over the years, destroy the system, creating in that downward path a two-tier system incompatible with the societal level which Canadians have attained." (Taylor, 1986).

Yet another commission that examined the health system and which, in 1986, introduced the final revisions to the Canadian legislation adopted this approach. The ensuing amendments brought about the situation described above — specifically, any physician or institution that treats patients within the framework of public funding or a public contract is for all practical purposes prohibited from receiving any private funding or from providing a SP package. That is, Canada opted for a fully segregated system to avoid the pitfalls of the combined system. 


\section{The Dilemma}

In a segregated system, publicly and privately financed demands compete for the same medical resources, manpower in particular, through disassociated provider institutions. In the combined system, those demands compete for those resources through the same provider institutions. The potential costs to the health system of the combined system are apparent. There can be an advantage, however, to this system for both economic and political reasons, especially in developing and outlying regions where medical resources are relatively scarce.

The practice of specialists and the use of expensive technology may be indivisible and subject to economies of scale. That is, it may be impossible or inefficient to divide theses resources between institutions. In addition, prevention of choice of any type, the provider of one's preference in particular, results in a decline in satisfaction, especially for those who can and are willing to pay for their choice. The nature of the demand, of well to do groups, on the one hand, and relative scarcity of supply, on the other, may leave the publicly financed system without some services altogether. That is, after all, there can be circumstances, when the less affluent stand a lesser risk of being denied particular services when those services are in the same provider institutions than otherwise (Chernichovsky 1995b, Chernichovsky and Potapchik 1997).

In addition, it is important to secure the political and financial support for public entitlement of middle and upper income groups. This support is critical for the lower socio-economic strata. The institutional integration of private and public contracts whereby these groups have more control over the services they receive -- may be, therefore, desirable and even inevitable in order to secure this support for public entitlement. 
Depending on the level of economic development and on the health system's affluence, the challenge is therefore to find a public-private mix of a nature that keeps different segments of the population relatively satisfied while minimizing the potential adverse consequences on the system of the implied public-private mix. The Emerging Paradigm in health system can help meet the challenge.

\section{Options and Directions under the Emerging Paradigm}

An essential feature of the Emerging Paradigm (EP) is the existence of budgetholding institutions that organize and manage the consumption of care (OMCC) in different ways under public entitlement. Provision of care is a prerogative of these institutions. Such institutions mediate between the state cum contributors to the public system, and its beneficiaries. Such are Health Maintenance Organizations (HMOs) or sickness funds of different types (Chernichovsky 1995a, 1998, 1997). ${ }^{21}$

OMCC institutions can co-exist alongside regular health insurers, and, if sanctioned, can manage care and provide private services as well as offer supplementary insurance for ancillary services (AS).

Health systems akin to the EP are the Russian, Israeli, Dutch, and the various arrangements with HMOs of the US Medicaid and Medicare programs. The EP is evolving also in Latin America, and may emerge in continental Europe once traditional insurers turn into $\mathrm{OMCC}$ institutions rather than becoming redundant financial administrators heavily regulated by the state. It is quite conceivable that groups of budget holders in the UK, and private insurers in Australia, for example, might eventually turn into such institutions.

When comparing a system with OMCC institutions to a system without (e.g., the Canadian or Australian systems), the former has a degree of flexibility as far at least 
as the nature of the public-private mix is concerned. Let us assume for the moment that OMCC institutions and insurers operate in a competitive market and that they do not provide medical services as such institutions may do.

Under these conditions the interest and the capacity of insurers and OMCC institutions -- as care managers -- to 'exploit' the patient is less than that same interest and capability for service providers. If an OMCC institution operating under a public contract provides also private insurance, it is in the OMCC institution's interest to see to it that services under public entitlement are fully rendered, before it pays for privately insured AS. Moreover, well-organized supplementary insurance can be a means to attract clients also for public entitlement (Brammli-Greenberg and Gross 1998). The incentive to safeguard against potential exploitation would be even greater when the OMCC is a not-for profit consumer association (Chernichovsky 1998).

Moreover, the proximity of OMCC institutions to providers helps safeguard effectively against potential exploitation of patients by the providers.

In a system with OMCC institutions and insurers that do not provide services, it is possible to sanction any of the options displayed in Table 3 and to rank order them in terms of their ability to serve the modern health system's objectives. The ranking is as follows:

1. Fully segregated system comprising pure public and private systems (in light gray shading), according to which private and public contracts cannot be combined at both OMCC and provider institution levels;

2. Semi-segregated system comprising combinations of types 1 and 5 whereby private and public contracts can be institutionally integrated at the OMCC/insurer level only;

\footnotetext{
21 The terms HMOs and sickness funds are used here generically, referring to different institutions
} 
3. Fully integrated system consisting of a combination of type 3 whereby private and public contracts can be integrated;

4. Semi segregated system made of combinations of type 2 and 4.

The ranking of options 2 and 3 is based on the premise that the OMCC institution has an incentive to safeguard that the services under the public contracts are rendered in full before it starts paying under private contracts. This follows because while it can be assured of the public contract and its terms, the OMCC institution needs to stay competitive under the private contract. That is, this institution may be an effective manager of the public-private mix. The ability of OMCC institutions to control the situation is better under option 2 where provision is segregated than under 3 where it is not. Option 4 is worst as providers have maximum scope to manipulate OMCC institutions and insurers in addition to patients.

To avoid situations whereby it is impossible or inefficient to duplicate services in separate privately and publicly financed provider institutions, both OMCC institutions and the government can establish special centers that constitute a combination of Type 3 (Table 3 ). That is, options 2 and 3 can coexist. The options outlined here become complicated when OMCC are also providers of services and hence have provider incentives.

Table 3: Possible Contracting Arrangements between Insurers/OMCC Institutions and Providers in Public and Privately Funded System

of this type including Preferred Provider Organizations (PPOs) and alike. 


\begin{tabular}{|l|c|c|c|}
\hline Service Provider & $\begin{array}{c}\text { OMCC /Insurer } \\
\text { public contracts } \\
\text { only }\end{array}$ & $\begin{array}{c}\text { Operating } \\
\text { public contracts } \\
\text { but authorized } \\
\text { to operate under } \\
\text { private } \\
\text { contracts }\end{array}$ & $\begin{array}{c}\text { Operating } \\
\text { under private } \\
\text { contracts only }\end{array}$ \\
\hline $\begin{array}{l}\text { Operating under public } \\
\text { contract,providing only the } \\
\text { BP }\end{array}$ & Purely public & $\begin{array}{c}\text { Combination } \\
\text { Type 1 }\end{array}$ & - \\
\hline $\begin{array}{l}\text { Operating under public } \\
\text { contract, but also authorized } \\
\text { to operate under private } \\
\text { contract }\end{array}$ & $\begin{array}{c}\text { Combination } \\
\text { Type 2 }\end{array}$ & $\begin{array}{c}\text { Combination } \\
\text { Type 3 }\end{array}$ & $\begin{array}{c}\text { Combination } \\
\text { Type 4 }\end{array}$ \\
\hline $\begin{array}{l}\text { Operating under private } \\
\text { contract only }\end{array}$ & - & $\begin{array}{c}\text { Combination } \\
\text { Type 5 }\end{array}$ & Purely private \\
\hline
\end{tabular}

Taking into consideration the above options, the question arises: "What are the optimal alternatives for a system under the Emerging Paradigm?" The answer depends on the level of integration of the OMCC and the provision functions in the OMCC institution. If OMCC institutions do not provide services, and, hence have no 'provider incentives', a system comprising types 1 and 5 would be optimal, with a possible addition of type 3 . In this case, OMCC institutions oversee contracts dealing with both public and private benefits, most likely under private insurance, potentially bringing fully to bear the advantages of these institutions. This solution adopts the 'Australian solution' for insurance, i.e., group rating and the right to private insurance, and the 'Canadian solution' for provision, i.e., separation of private and public contracts. The Australian regulation of private insurance can contribute to equity and cost control. A combination of type 3 offers a potential correction for problems of indivisibilities and economies of scale. 
If, however, the OMCC institution also provides care, then the fully segregated system would be desirable. Intermediate situations are also envisioned, whereby the OMCC institutions provide private insurance for those services it does not provide in house.

\section{Conclusion}

A priori, there is a wide scope for providers to thwart the objectives of the publicly financed health system when a supplementary package or a combined system is sanctioned. This follows (a) the impossibility to define precisely a BP, and (b) the prevailing incentives of providers, especially under prospective reimbursement schemes, to exploit the clients and the public system. Consequently, the authorization of a combined system defies the cost containment and equity objectives of the modern publicly supported health system, and the efforts to provide a quality social package or public entitlement.

The government can mitigate the situation by following a rational policy whereby public benefits are based on cost-benefit considerations, and by educating and informing the public about medical care processes and outcomes. In addition, a prudent policy should minimize the options for proximity between 'public' and 'private' at the point of services provision, especially with regard to 'excluded services' which are real or virtual substitutes for services included in public entitlement. Where the combined system is inevitable, the Emerging Paradigm can offer a viable solution to the public private mix.

\section{Appendix}

Suppose the original situation is marked by the quantity demanded $\mathbf{Q}_{\mathbf{c}}$ and the cost or unsubsidized price $\mathbf{P}_{\mathbf{c}}$. For any lower subsidized price $\mathbf{P}_{\mathbf{i}}(\mathbf{i}=\mathbf{0 , 1})$, the cost to the budget $\mathbf{B}$, is 


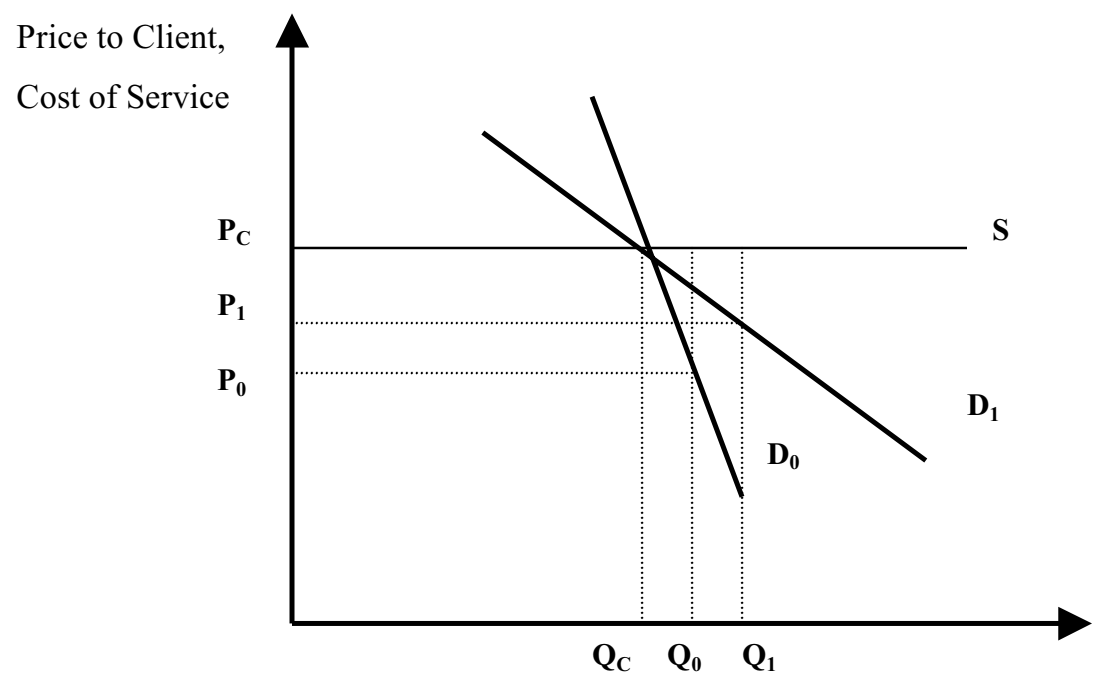

(1) $\quad B=\left(P_{c}-P_{i}\right) Q_{i}$

for any $\mathbf{P}_{\mathbf{i}}$ that is lower than $\mathbf{P}_{\mathbf{c}}$ and corresponding $\mathbf{Q}_{\mathbf{i}}$. As

(2) $\frac{\Delta \mathbf{Q}}{\mathbf{Q}_{\mathbf{c}}}=/ \eta_{\mathrm{i}} / \frac{\Delta \mathbf{P}}{\mathbf{P}_{\mathbf{c}}}$,

Where

(3) $\Delta \mathbf{Q}=\mathbf{Q}_{\mathrm{i}}-\mathbf{Q}_{\mathrm{c}}$,

(4) $\Delta \mathbf{P}=\mathbf{P}_{\mathbf{c}}-\mathbf{P}_{\mathrm{I}}$

and $/ \eta_{\mathrm{i}} /$ is the absolute value of the demand elasticity in the relevant range.

Alternatively:

(5) $\Delta \mathbf{Q}=/ \eta / \frac{\Delta \mathbf{P}}{\mathbf{P}_{\mathbf{c}}} \mathbf{Q}_{\mathbf{c}}$.

As, following (1)

(6) $\Delta \mathbf{Q}=\left(\mathbf{P}_{\mathrm{c}}-\mathbf{P}_{\mathbf{i}}\right)=\frac{\mathbf{B}}{\mathbf{Q}_{\mathbf{i}}}$,

by substituting (6) in (5)

(7) $\Delta \mathbf{Q}=\mathbf{Q}_{\mathrm{i}}-\mathbf{Q}_{\mathbf{c}}=/ \eta / \quad \mathbf{B} \mathbf{Q}_{\mathbf{c}} /\left(\mathbf{Q}_{\mathbf{i}} \mathbf{P}_{\mathbf{c}}\right)$.

That is, the quantity change is higher for any budget $\mathbf{B}$, the higher the demand elasticity $/ \eta /$, as indicated by $\mathbf{Q}_{\mathbf{i}}$, compared with $\mathbf{Q}_{\mathbf{c}}$, vis a vis $\mathbf{Q}_{\mathbf{0}}$ compared with $\mathbf{Q}_{\mathbf{c}}$. 


\section{References}

Antonovsky, A. 1987. Unraveling the Mystery of Health. San Francisco: Jossey-Bass.

Arrow, K.J. 1963. Uncertainty and Welfare Economics of Medical Care. The American Economic Review 53(5):941-973.

Bramli-Greenberg, S. and R. Gross. 1998. Supplemental and Commercial Health Insurance, 1998: Changes in Policy, Financing and Consumer Behavior. Jerusalem: JDC-Brookdale Institute (RR): 349-99.

Chernichovsky, D. 1995a. Health System Reform in Industrialized Democracies: An Emerging Paradigm. The Milbank Quarterly 73(3):339-372.

Chernichovsky, D. 1995b. What Can Developing Economies Learn from Health System Reforms of Developed Economies? Health Policy. 32:79-91.

Chernichovsky, D. 1996. Democratization in Health Systems Under the Emerging Paradigm; Capitation Revisited. Bitahon Socialli 47:9-31 (in Hebrew, English version processed).

Chernichovsky, D. 1997. "A Structured Approach Toward Solving the Enigma of Healthcare System Financing." Helsinki: WHO meeting on Health for All Renewal -Building Sustainable Health Systems: from Policy to Action.

Chernichovsky, D. 1998. Public Choice, Pluralism, and the State in the Emerging Paradigm of Health Systems. Sydney: Meetings of the Australian Health Economics Association.

Chernichovsky, D. and D. Chiniz. 1995. The Political Economy of Health System Reform in Israel. Health Economics 4:127-141.

Deeble, J. and P. Lewis-Hughes. 1991. Directions for Pathology. Melbourne: National Health Strategy. Background Paper 6.

Grossman, M. 1972. The Demand for Health: A Theoretical and Empirical Investigation. National Bureau of Economic Research. New York: Columbia University Press Occasional Paper 119.

Hurst J.W. 1991. Reforming Health Care in Seven European Countries. Health Affairs 10:7-21.

Schneider, M., Dennerlein, R. K. H., Kose, A. and L. Scholtes. 1992. Health Care in the EC Member States. Health Policy. Special Issue. 20(1,2).

Taylor G.M. 1986 The Canadian Health Care and System 1974-1984. In Medicare at Maturity; Achievements, Lessons and Challenges, ed.Evans R.G. and G.L. Stoddart. Calgary: The University of Calgary Press.

The Manchester Unity Friendly Society. 1991. "Rates Rise, But Why?" The Communicator. Melbourne, March. 
Wagstaff, A. and E. van Doorslaer. 1992a. Equity in the Delivery of Health Care: Some International Comparisons. Journal of Health Economics 11:389-411.

Wagstaff, A. and E. van Doorslaer. 1992b. Equity in the Finance of Health Care: Some International Comparisons. Journal of Health Economics 11:361-387.

Waldby, J. C. n.d. "The Influence of Health Insurance Status on The Organization of Patient Care in the New South Wales Public Health System." Faculty of Medicine. University of Sydney.

Wilcox, S. 1991 A Health Risk? Use A Private Insurance. Melbourne. National Health Strategy Group. Background Paper 4.

Williams, S.J. and M. Calnan. 1996. The 'Limits of Medicalization?: Modern Medicine and the Lay Populace in 'Late Modernity'. Social Science and Medicine. 42(12):1609-1620. 